\title{
Optimising the energy consumption on pultrusion process
}

\author{
F.J.G. Silva, F. Ferreira, M.C.S. Ribeiro, Ana C.M. Castro, M.R.A. Castro, M.L. Dinis, A. Fiúza
}

\begin{abstract}
A B S T R A C T
This study is based on a previous experimental work in which embedded cylindrical heaters were applied to a pultrusion machine die, and resultant energetic performance compared with that achieved with the former heating system based on planar resistances. The previous work allowed to conclude that the use of embedded resistances enhances significantly the energetic performance of pultrusion process, leading to $57 \%$ decrease of energy consumption. However, the aforementioned study was developed with basis on an existing pultrusion die, which only allowed a single relative position for the heaters.

In the present work, new relative positions for the heaters were investigated in order to optimise heat distribution process and energy consumption. Finite Elements Analysis was applied as an efficient tool to identify the best relative position of the heaters into the die, taking into account the usual parameters involved in the process and the control system already tested in the previous study. The analysis was firstly developed based on eight cylindrical heaters located in four different location plans. In a second phase, in order to refine the results, a new approach was adopted using sixteen heaters with the same total power. Final results allow to conclude that the correct positioning of the heaters can contribute to about $10 \%$ of energy consumption reduction, decreasing the production costs and leading to a better eco-efficiency of pultrusion process.
\end{abstract}

Keywords:

A. Glass fibres

C. Finite Elements Analysis (FEA)

D. Thermal analysis

E. Pultrusion

\section{Introduction}

Composite materials, presenting a high strength to weight ratio, are becoming more and more widespread into the worldwide, forming the core of the major part of technologic products of the modern world. Nowadays, among the several available techniques to produce and manufacture composite materials, pultrusion process is the oldest continuous processing technique and, until now, is still the most cost-effective one, in particular for manufacturing fibre reinforced polymer (FRP) components with a constant cross-section [1].

FRP profiles, based either on glass, carbon or aramide fibres reinforced thermoset or thermoplastic matrix polymers, even with complex cross-section geometries, are easily attained by pultrusion process. One of the main attractions of this manufacturing method is the simplicity of tooling and low labour requirements. In this process, typically, dry reinforcement fibres, in the form of continuous strands (rovings) or plys (mats, fabrics and veils), are pulled through a resin bath for impregnation, and after wetting process, the reinforcement pack is collimated in a progressive manner into a performed shape before entering the heated die where it attains the final form of the die cavity and cures. The die may be heated by external or internal electrical heaters, strip heaters, hot oil or by steam, although external electrical heaters are the most common ones. Finally, outside the die, the composite part already polymerised and consolidated is pulled by a continuous pulling system and then a cut-off saw cuts the part into a desired length [2]. A schematic overview of pultrusion process and the equipment employed is shown in Fig. 1.

In spite its relative simplicity, the continuous nature of the process lays constraints on the quality control system due the numerous interdependencies of the control variables. For the same product composition and cross-section, pulling speed, pulling force, die length and heating die system are interdependent variables that affect the quality of final pultruded product [4]. To achieve a uniform degree of cure, the temperature profile (TP) inside the forming die is a crucial aspect to take into account, and the fine-tuning of this TP according to material composition, composite part cross-section and dimensions, is not a straightforward task. Besides the variables already mentioned, other kinetic parameters are involved such as reactivity and exothermic reaction of resin matrix. In fact, as the fibre-resin matrix enters and proceeds along the length of the heated die, the exothermic reaction of 


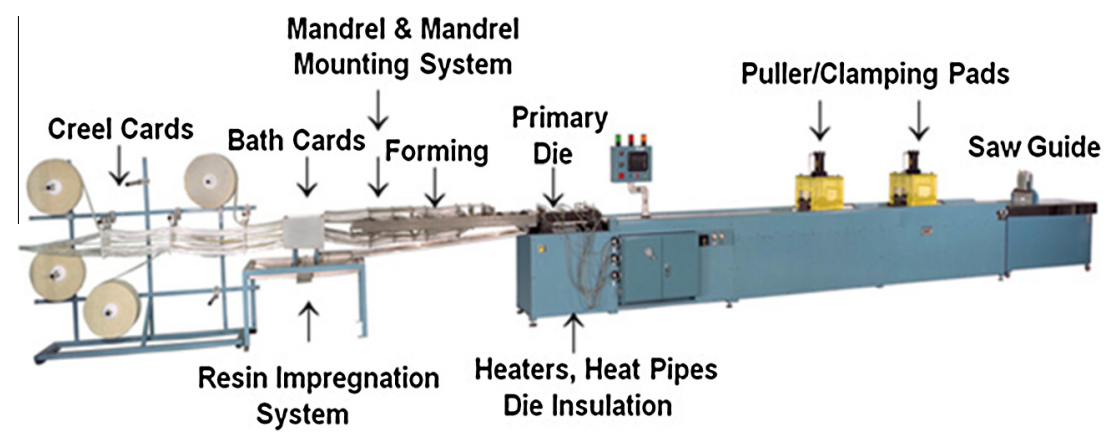

Fig. 1. Schematic diagram of pultrusion process [3].

polymerisation starts, thereby releasing heat and raising the temperature of the composite above that of die-wall. After exothermic peak, the composite starts losing heat to the die wall through conduction as it proceeds along the die, and through convection and radiation to the surrounding environment upon exiting the die. Therefore, the TP in the composite material inside the forming die is a balance of heat transfer, generated by heating die system and exothermic reaction of resin matrix $[5,6]$.

Several thermodynamic models have been developed to reach a fundamental understanding of kinetic-parameter relationships of pultrusion process. An exhaustive review of applied models can be found in Moschiar et al. [7]. Most of research work that has been done in this field aims to optimise the TP and processing parameters for a given composite material to be produced, using numerical models based on different approaches, including finite element and finite difference techniques.

\subsection{Numerical models applied to the optimisation of pultrusion process}

The finite-difference method was applied by Sarrionandia and Mondragón [8] to calculate the temperature and conversion profiles for a fiberglass/modified acrylic pultruded composite, while analysing the effects of several process variables: pulling speed, die temperature, composite thickness and fibre content. A good agreement was found between numerical values and experimental data at different pulling rates. Safonov and Suvorova [9] also used the finite-difference approach to numerically solve the governing equations of heat transfer and curing reaction related to pultrusion process of a fiberglass/epoxy rod with a large diameter. The proposed mathematical model allowed varying several processing and material parameters (pulling speed, die sizes, rod geometry, heating temperature and epoxy system composition), towards the optimisation of the process.

A control-volume finite-difference method (Patankar method) was used by Gorthala et al. [10] to obtain temperature and degree of cure profiles in the manufacturing processes of graphite/epoxy and fiberglass/epoxy composites. This method was found to be reliable for solving the related governing equations of resin flow, cure and heat transfer. Valliappan et al. [6] also developed a numerical model using a fixed control-volume based on finite-different approach to predict the die and post-die temperature, and degree of cure of a graphite/epoxy pultruded composite with cylindrical shape geometry. Pull speed, die-wall temperature setting and fibre volume fraction, were considered as processing variables. A good agreement was obtained between predicted and experimental values. The post-die curing was also found to be a significant feature during pultrusion process.

Suratno et al. [5] applied a two-dimensional finite-element model to simulate heat transfer and TPs inside the die during the pultrusion process of carbon/epoxy composite rods. The model was coupled with a numerical approximation of the curing kinetics for thermosetting polymers. Obtained results were compared and fitted with experimental values acquired in previous research.

Liu and Hillier [11] used a finite-element/control-volume procedure to simulate heat transfer and curing process of a pultruded fiberglass/vinyl ester I beam, for different temperature settings and pull speeds. The numerical simulation allowed optimising the proper combination of these two process parameters for the analysed composite. Posteriorly, Liu et al. [12] developed a new finite-element/finite-difference/control-volume procedure to solve the governing equations for heat transfer and resin curing reaction. The procedure revealed to be numerically stable and allowed to predict with good accuracy temperature and cure profiles when compared with results obtained by other researchers.

Joshi, Lam and co-workers [13-16], developed and thoroughly applied the finite-element/nodal-control-volume (FE/NCV) approach for the three-dimensional analysis of pultrusion process, with focus on different features of the process or on material factors of pultruded composite. In Joshi and Lam [13], this approach was applied to several case studies in order to calculate the effects of convective heat-transfer on temperature and degree of cure, and for determining the dimensional changes of pultruded part due to thermal expansion and shrinkage of resin matrix; in Lam et al. [14], the 3D FE/NCV procedure was used to achieve the optimum combination of die-heater temperature and pull speed for a graphite/ epoxy C-section composite; in Joshi et al. [15], the same procedure was applied aimed at fine-tuning the desired degree of cure for a fiberglass/epoxy composite relied on pre-heating and die-cooler temperature controls; finally, in Joshi and Lam [16], the feasibility of this method at modelling the crystallization of thermoplastic binders in pultrusion process is discussed and compared with homologous model related with the polymerisation of thermoset binders. In all the aforementioned research works, FE/NCV approach revealed to be numerically stable, robust and reliable.

A different approach, a combination of finite-element method, finite-difference method and indirect decoupling method, was used by Chen et al. [17] to solve the governing equations in the pultrusion process of carbon fibre reinforced polymer (CFRP) rods. On the basis of simulated results, previously validated by experimental data, an optimisation process of pull speed and die temperature parameters was performed based on genetic algorithm (GA) and artificial neural network (ANN). Applied method was effective at determining the optimal parameters, with an increase of pull speed and a decrease of die temperature, without violating the constraints of degree of cure.

Although the use of environmentally and health-friendly technologies is becoming, nowadays, increasingly important, none of the aforementioned research studies deal with the optimisation of pultrusion process from the energy-consumption point of view. 


\subsection{Energy issues on manufacturing processes}

Due to growing concern with ecologic footprint, environmental impact of manufacturing processes and systems has been more and more focused on energy consumption patterns. Energy consumption is an important component of environmental impact and constitutes a critical issue in any overall sustainability strategy [18]. If manufacturing systems are managed to minimise energy usage, the operating costs are lowered and, on the other hand, the undesirable environmental impact from energy generation (carbon dioxide emissions) is reduced [19]. Hence, this led that the use of eco-efficiency ratios, such as volume (or mass) of material processed per unit of energy consumed, has been steadily growing over the past decade and became a common approach for the assessment of manufacturing processes sustainability [18-20].

Though, there's still a strong inertia in the industrial organizations in changing procedures or adopting different technical approaches on their processes in order to reduce energy consumption and, hence, improve eco-efficiency ratios. Even small changes, especially on well-established and large scale manufacturing processes such as pultrusion, usually imply large investments with long-term outcomes. Thus, all measures to be proposed in this field must be based on strong and reliable assumptions. Thermodynamic simulations revealed to be an efficient tool in this practice. As already stressed by Franco and Romoli [18], researchers dealing with this topic are consensual about the idea that thermodynamics is particularly suitable to develop reliable and efficient criteria focused on the optimisation of different manufacturing techniques based on the concept of reduction of energy waste

\subsection{Energy savings on pultrusion manufacturing processes}

Under this scope, regarding pultrusion manufacturing process, Khan and Methven [21] analysed and quantified by thermal simulation the duty cycle of the die heating system of a typical pultrusion process, and thereby, provided an estimation of the Specific Energy Consumption (SEC). The effect of preheating the precursors on line speed was also analysed. For that purpose, different input temperatures of the die were analysed, the heating and cure curves (TPs) were plotted for the composite material inside the die and, then, the simulation was extended for the duty cycles of the die heating system.

Sumerack [22] performed an experimental study undertaken the different conditions at the pultrusion die-planar heaters interface and their effects on process stability and energy consumption. Focused on external heaters system, the study highlights the importance of heaters design, mounting method and routine maintenance on process quality and economics. It was found that the use of conductive heat transfer paste in the heater/die interface, jointly with a heater surface maintenance procedure, lead to the greatest process efficiency, minor heat losses, lower energy consumption (low duty cycle of heaters) and improved product cure consistency.

Srinivasagupta and Kardos [23] used a thermodynamic objective function to minimize the energy consumption during the cure reaction in an injected pultrusion (IP) process. As the same way as the other previous researches in the field, the authors considered that the number, geometry and position of the heaters were predefined and known before the numerical optimisation, and the pultrusion process was modelled according to the previous heaters arrangement.

In all of the aforementioned studies, none considerations were done regarding the effects of changing heaters relative position on the energy consumption. In order to fulfil this gap, a different approach was used by Santos et al. [24,25]. Instead of conventional external heaters, they suggested an alternative die configuration with internal heaters aimed at increasing the number of arrangement possibilities and, hence, enabling the determination of the best arrangement that minimizes the energy rate and consumption. In the optimisation process a numerical procedure based on computational fluid dynamics (CFD) technique and on a stochastic optimisation algorithm (PSO-Particle Swarm Optimization) was applied. It was found that the optimisation with internal heaters was successful in finding a better way to cure the resin in a more uniform way, while minimising the energy rate. Despite the good results and the efficiency of applied model, published studies do not elucidate on how the optimisation process could be enhanced in order to contemplate different relative positions of internal heaters.

A previous research study conducted by the present authors, Silva et al. [26] also showed a significant reduction on energy consumption that could be obtained using embedded cylindrical heaters into the die instead of external planar resistances. It was found that embedded resistances significantly enhance the energetic performance of pultrusion process, leading to $57 \%$ decrease of energy consumption exclusively due to die heating system. Experiments were conducted on a $900 \mathrm{~mm}$ length die during the manufacturing process of a fiberglass/polyester U-shape profile while keeping the other process parameters constant: pulling speed, pulling force, total resistance power and TP along the die. These process parameters were already fine-tuned over the years by the large experience of the manufacturer and conduct to a high standard of quality of pultruded part. TP was first experimentally obtained by thermography techniques, for the planar heating system, and then numerically simulated by finite-element analysis (FEA) with basis on heat-transfer models. After validation of FEA simulation, energy consumption with internal heating system was simulated and predicted using the same technique.

However, the above study was developed based on an existing pultrusion die, which only allowed a single relative position for the embedded heaters. It is believed that, for the previously achieved fine-tuned TP and processing parameters, the relative position and duty cycle of the internal heaters could be optimised in order to achieve further savings on energy consumption. Within this scope, in the present study, new relative positions for the embedded heaters were investigated aimed at optimising heat distribution process and energy consumption. FEA was anew applied, as a resourceful tool to identify the best relative position of the heaters into the die, taking into account the usual parameters involved in the process and the control system already tested in the previous study.

\section{Applied model and methodology}

Both analyses, in the previous and present studies, were focused on the pultrusion manufacturing process of a GFRP U-shape profile with the following cross-section: $51 \mathrm{~mm}$ width, $12 \mathrm{~mm}$ height and $4 \mathrm{~mm}$ thickness. The length, width and height of die tool used in the manufacturing process of this specific profile were, respectively, $900 \mathrm{~mm}, 103 \mathrm{~mm}$ and $56 \mathrm{~mm}$; and the process and material parameters, already fine-tuned by the manufacturers, were as follows:

- Glass fibres: Type E (34 fibre wires with 4800 TEX).

- Resin type: unsaturated polyester resin, with a gel time of $2 \mathrm{~min}$. and an exothermic peak of $230^{\circ} \mathrm{C}$.

- Resin/fibre weight ratio: 30/70.

- Pulling speed: $50 \mathrm{~cm} / \mathrm{min}$; pulling force: $6 \mathrm{kN}$. 


\subsection{Previous analysis}

A general description of performed analysis is given here. For a more detailed explanation refer to Silva et al. [26].

The previous die heating system consisted of four external planar heaters, with $800 \mathrm{~W}$ each, formed by $\mathrm{Cr}-\mathrm{Ni}$ spiralled wire embedded in a cast aluminium block, and divided in two groups: ' $A$ ' and 'B'. Each group comprised two heaters mounted through clamps on the upper and lower sides of the die. Length, width and height of heaters of group ' $A$ ' were $350 \mathrm{~mm}, 70 \mathrm{~mm}$ and $30 \mathrm{~mm}$, while correspondent dimensions of those of group 'B' were $380 \mathrm{~mm}, 140 \mathrm{~mm}$ and $30 \mathrm{~mm}$, respectively. As all the heaters had the same power, size differences only influenced the ratio $\mathrm{W} / \mathrm{m}^{3}$. Two temperature sensors, one for each group of heaters, sent real-time information to a PLC (Programmable Logic Controller), which monitored the duty cycle of the heaters. Set-point temperatures of groups 'A' and ' $B$ ', for the production of U-shape profile were, respectively, $140^{\circ} \mathrm{C}$ and $195^{\circ} \mathrm{C}$, with an allowed temperature variation range of $\pm 5^{\circ} \mathrm{C}$. This means that the power supply switches between 'on' and 'off' when the temperature is, respectively, $5{ }^{\circ} \mathrm{C}$ below or above the reference temperatures. Temperature variation ranges up to $\pm 4 \%$, or even $\pm 5 \%$, with regard to the die temperature set points (in ${ }^{\circ} \mathrm{C}$ ) are within the acceptable limits usually applied in pultrusion processes. In this particular case, $\pm 5^{\circ} \mathrm{C}$ correspond to $\pm 2.6 \%$ and $\pm 3.6 \%$ of the highest and lowest temperature set points, respectively $\left(195^{\circ} \mathrm{C}\right.$ and $\left.140^{\circ} \mathrm{C}\right)$.

Thermographic images were taken by means of a Flir ${ }^{\circledR} \mathrm{i} 40$ imaging camera during a stable manufacturing state, which allowed assessing the TP along the die. Thermographic measurements were made on both lateral sides of the die and referred as one single session. Three sessions were run on three different working days under similar environmental and processing conditions. Each acquired image was divided into 100 different areas corresponding to a matrix with 4 rows and 25 columns representing the lateral face of the die. The Flir ${ }^{\circledR}$ Quick Report software package and statistical tools were applied to all images, and for each image, an average temperature was collected at the interception points of the matrix. Finally, the results obtained from all images throughout the three sessions were averaged to obtain the TP along the die, as shown in graph of Fig. 2(a).

FEA was then applied to solve the energy balance equation and to model the die tool-heaters system. The thermal state was assumed to be transient and the following assumptions were presumed: (a) all contacts were considered as perfect; (b) all bodies were initially at room temperature $\left(22^{\circ} \mathrm{C}\right)$, which remained constant; and (c) the convection coefficient and the emissivity were assumed, respectively, equal to $2 \mathrm{~W} / \mathrm{m}^{2}{ }^{\circ} \mathrm{C}$ and 0.8 . Die tool was modelled as upper and lower parts and the heaters were modelled as independent bodies. A tetrahedral (four nodes) mesh was used, which, after convergence resulted in 256,975 elements (for half of die tool taking advantage of its symmetry) (Fig. 2 $\mathbf{b}_{2}$ ).

The reference points chosen for the temperature control in the simulation corresponded to those where the temperature sensors of the group of heaters ' $\mathrm{A}$ ' and 'B' were located on the real die, respectively at $720 \mathrm{~mm}$ and $216 \mathrm{~mm}$ of die entrance. The temperature at these points was checked with the drawn TP obtained by thermography and was used as a reference to perform the FEA, allowing the fine-tuning and convergence of the analysis. The simulation ran for $4500 \mathrm{~s}$ (3600 s corresponding to a warm-up period and further $900 \mathrm{~s}$ corresponding to a stable operational phase). At the end of the simulation, both the duty cycle of the heaters and the TP values along the die were obtained and compared with data acquired by PLC and thermography. As shown in graph of Fig. 2, a good agreement between the TP drawn by thermography and the TP obtained by FEA was achieved. The large mismatch between the two curves at die entrance was due to operational reasons: this part of the die tool was located behind the fastening elements used to fix the die to pultrusion base equipment, blocking locally the camera's infra-red beam during thermography measurements. Also a good agreement was attained between estimated duty cycle of the heaters and data collected through the PLC validating the FEA model.

In the second phase of this previous study, aiming to improve thermal efficiency and reduce heat losses and warm-up period, the external planar heaters were replaced by cylindrical heaters embedded on die tool as displayed in Fig. 3. The new heating system was constituted by four independent groups of heaters that comprised, individually, two heaters with $400 \mathrm{~W}$ and a temperature sensor. Total power applied to the system remained equal to $3.2 \mathrm{~kW}$ but was more distributed along the die, enabling a more precise control of temperature due to its four temperature sensors. The PLC of the pultrusion machine was capable of controlling up to four channels and the resistances were inserted along the die into

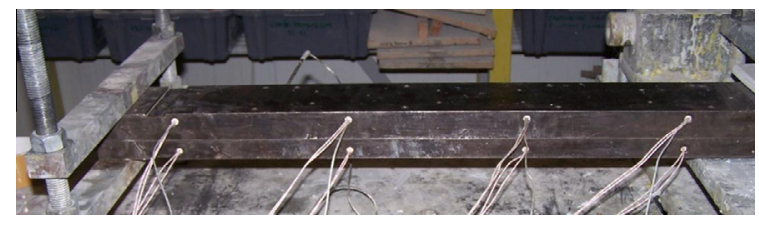

Fig. 3. Cylindrical embedded heaters along die tool.
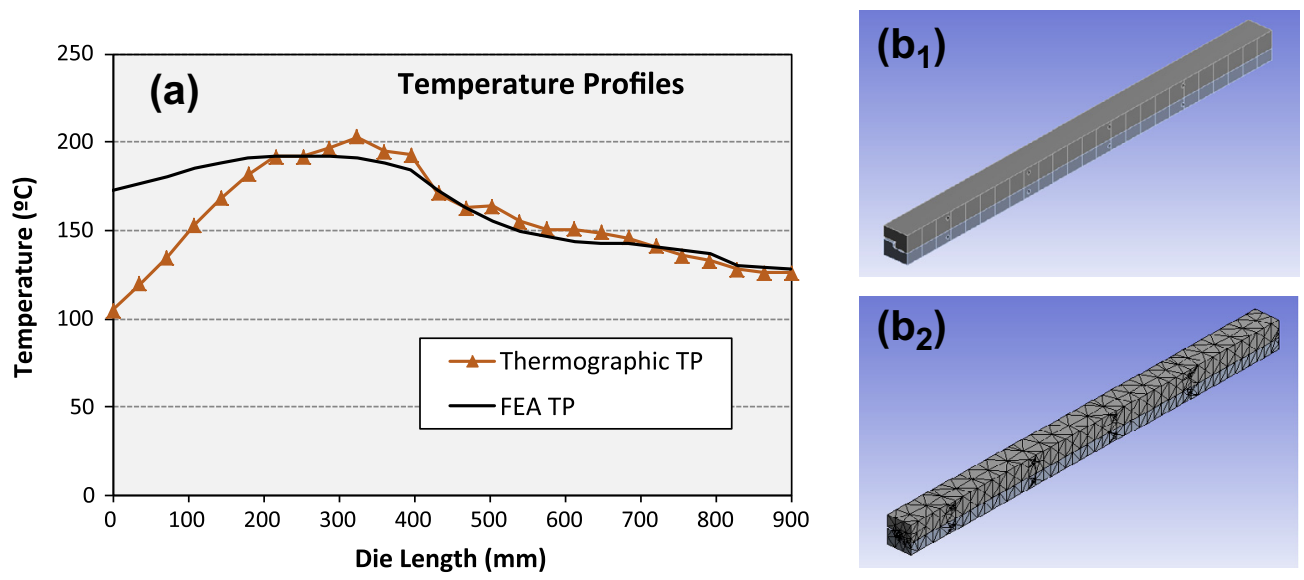

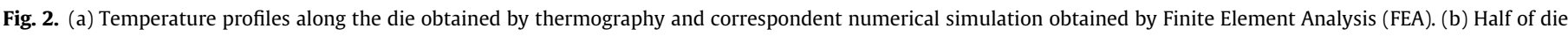
tool, with $\left(b_{2}\right)$ and without $\left(b_{1}\right)$ the mesh used for FEA. 
existing holes, formerly conceived and used to accommodate temperature probes.

The new heating system was simulated with the same assumptions used previously for the planar heating system and assuming the same predefined TP. Temperature was controlled at pertinent points near each pair of heaters considering limits of allowable variation of $\pm 5{ }^{\circ} \mathrm{C}$. The reference temperature for each one of the four points was obtained by the thermographic TP, using the same proceeding that was considered in the first analysis. A tetrahedral mesh was used, which, after convergence, resulted in 11,089 elements. As the same way as formerly, aiming to reduce the computation effort, only half of the die tool was simulated taking into account the geometric symmetry along die length. The duty cycle of the embedded heaters was obtained at the end of the simulation and then, on the basis of obtained results, the total power consumptions of both heating systems during an entire working day $(8 \mathrm{~h})$ were computed and compared.

It was found that the new heating system allows a saving of $57 \%$ on energy consumption, as well as a reduction of $50 \%$ on warm-up period, improving both energy performance and production times. Though, it is believed that the relative position of the embedded heaters along the die could be optimised in order to achieve a higher reduction on energy consumption, which endorses the present study.

\subsection{Present research study}

The experimental set-up used to validate the process model in the previous study forms a reference against which the present optimisation studies and resultant retrofit design can be benchmarked.

Four different relative positions (layouts) of the heaters were analysed and correspondent duty cycles were estimated by FEA using the previous methodology. Analysed relative positions of group of heaters, or layouts, are schematized in Fig. 4.

- Layout 1: corresponds to the previous relative position of the embedded heaters, and will be used as reference. This layout was experimentally implemented in the former research study taking advantage of the existing holes on the die.

- Layouts 2 and 3, correspond to relative positions of the heaters in which TP was taken into account. The criterion was positioning the heaters in correspondence with TP, more concentrated in the first half of the die where the temperature reaches higher values. For defining Layout 2, the area beneath the curve of TP obtained by FEA was calculated and divided into four equivalent sectors with the same areas $\left({ }^{\circ} \mathrm{C} \mathrm{mm}\right)$. For each sector, the abscissa of the centroid was calculated and used as reference for the positioning plan of the groups of heaters. Layout 3 follows the same principle, but considers the three first groups of heaters ( $\mathrm{GH} 1, \mathrm{GH} 2$ and $\mathrm{GH} 3$ ) more concentrated near the peak of TP.

- Layout 4, correspond to a symmetric and homogeneous disposition of the heaters along the die.

A mesh with tetrahedral elements with edges of $0.01 \mathrm{~m}$ length was chosen as leading to an excellent relationship between accuracy and computational efforts, when compared with other tested meshes (four nodes meshes with $0.1 \mathrm{~m}, 0.05 \mathrm{~m}, 0.008 \mathrm{~m}$ and 0.003 m edge lengths)

\section{Results and discussion}

For each analysed layout, duty cycles of the four pair of heaters obtained by numerical simulation are displayed in graphs of Fig. 5.

Die Inlet

\section{Die Outlet}

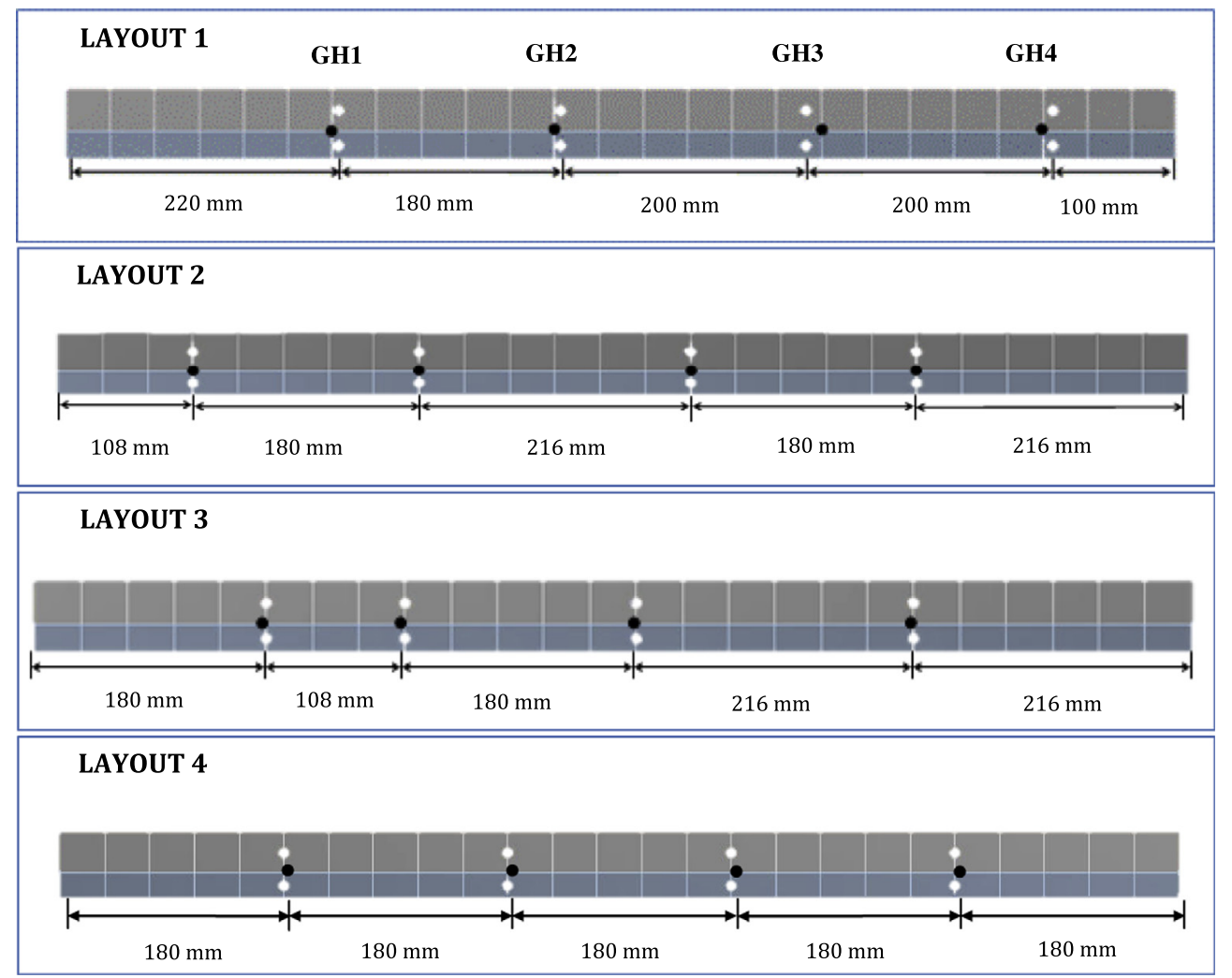

Fig. 4. The relative position of the heaters analysed in this study (white spots) and correspondent temperature control points (black spots). 
For all the systems, duty cycles of each pair of heaters, required time for heating-up stage, power consumption per hour during both warm-up and manufacturing periods, as well as total energy consumption (TEC) for a normal working day of $8 \mathrm{~h}$, are presented in Table 1. Duty cycles of the heaters are notated as periods of time 'Switch-on/Switch-off' and correspond to average periods of time obtained by simulation, in a stable phase, after warming period. Power consumption per hour during manufacturing time was calculated based on average time of duty cycles of the heaters. Total energy consumption, in $\mathrm{kW}$, was computed as follows:

$\mathrm{TEC}=\mathrm{PC}_{\mathrm{W}} \mathrm{T}_{\mathrm{W}}+\mathrm{PC}_{\mathrm{M}}(8-T W)$ where $\mathrm{PC}_{W}$ and $\mathrm{PC}_{M}$ correspond to the sum of power consumption of all groups of heaters during, respectively, warm-up and manufacturing periods, in $\mathrm{kW}$ per hour; and $T_{W}$ stands for period of time, in hours, required for heating-up stage. In Table $1, \mathrm{PC}_{W}$ and $\mathrm{PC}_{M}$ are also discretized by group of heaters. The criterion applied to define $T_{W}$ was establish as the period of time after which all groups of heaters presented a stable pattern of duty cycle with regular times of switch-on and switch-off, as marked in graphs of Fig. 5.

As it can be observed in Table 1, when comparing the needs of power consumption per manufacturing day of each relative position of group of heaters, some quite significant differences were found between analysed layouts.

LAYOUT 1 -Duty cycle of group of heaters

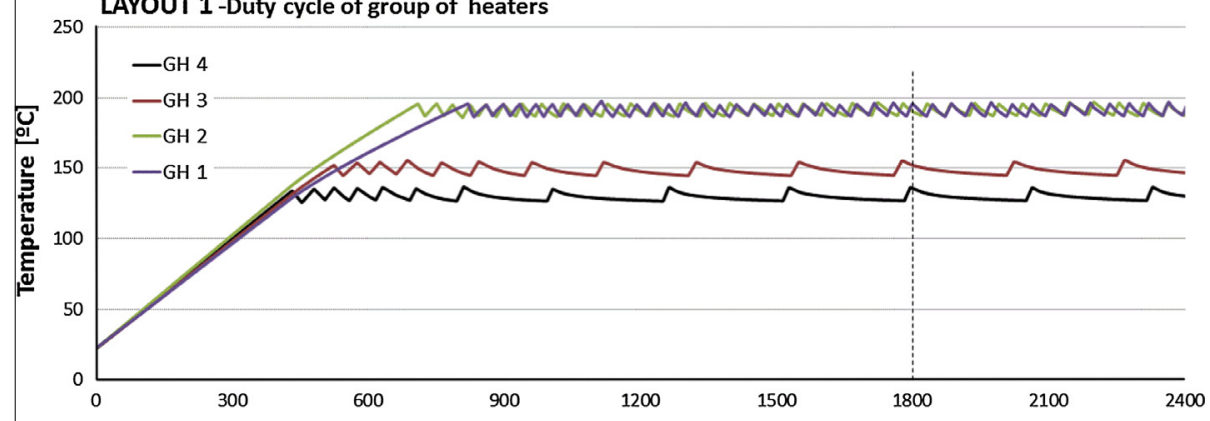

LAYOUT 2 -Duty cycle of group of heaters

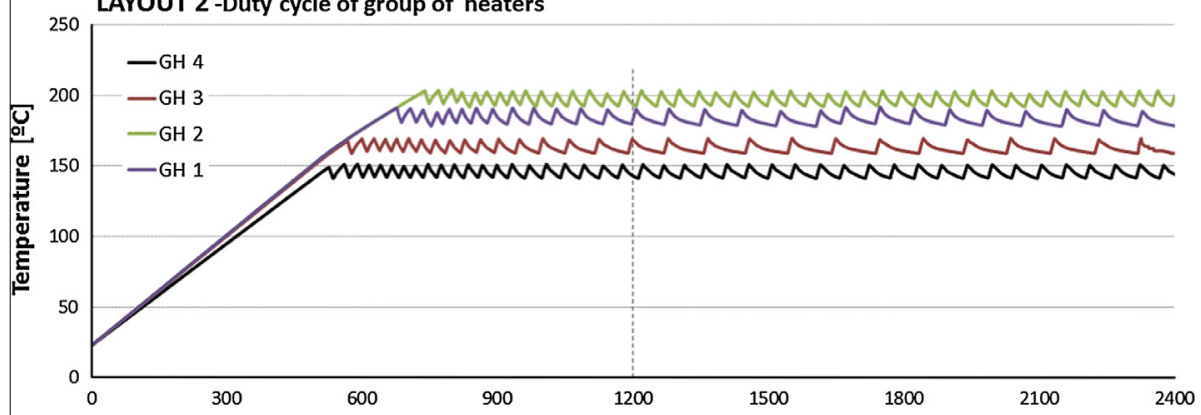

LAYOUT 3 -Duty cycle of group of heaters

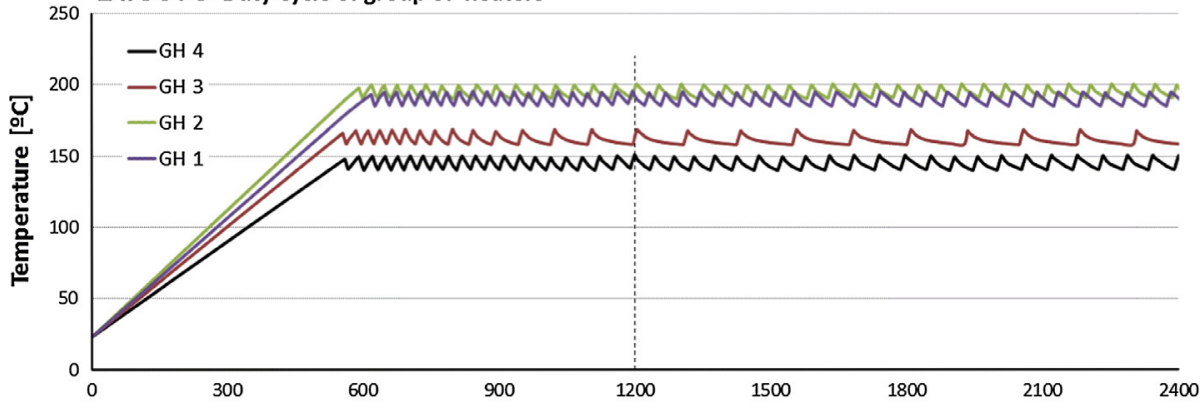

LAYOUT 4 -Duty cycle of group of heaters

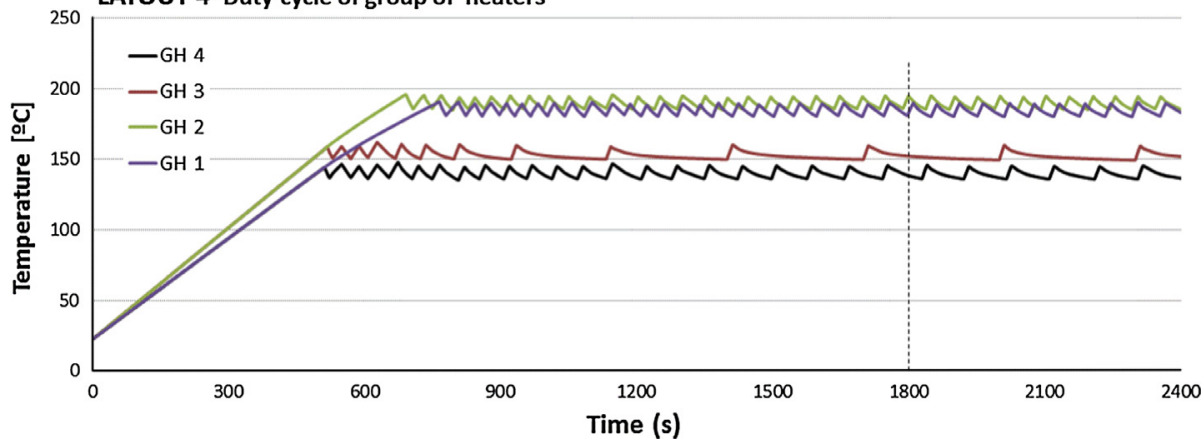

Fig. 5. Duty cycle of group of heaters obtained by FEA simulation for each analysed layout. 
Table 1

Warming-up periods, duty cycles, power consumptions and total energy consumption of 4 groups of heaters ( $2 \times 400 \mathrm{~W})$ for Layouts 1 to 4 .

\begin{tabular}{|c|c|c|c|c|c|c|}
\hline Layout & Heaters & $T_{W}(\mathrm{~s})$ & Duty cycle (s) & $\mathrm{PC}_{\mathrm{W}}(\mathrm{kW} \mathrm{h})$ & $\mathrm{PC}_{\mathrm{M}}(\mathrm{kW} \mathrm{h})$ & TEC (kW) \\
\hline \multirow[t]{4}{*}{ Layout 1} & GH 1 & \multirow[t]{4}{*}{1800} & $12.2 / 35.2$ & 0.538 & 0.206 & \multirow[t]{4}{*}{4.350} \\
\hline & GH 2 & & $12.2 / 42.2$ & 0.443 & 0.179 & \\
\hline & GH 3 & & $15.7 / 217.0$ & 0.312 & 0.054 & \\
\hline & GH 4 & & $12.1 / 241.9$ & 0.258 & 0.038 & \\
\hline \multirow[t]{4}{*}{ Layout 2} & GH 1 & \multirow[t]{4}{*}{1200} & $9.2 / 67.3$ & 0.545 & 0.096 & \multirow[t]{4}{*}{4.451} \\
\hline & GH 2 & & $10.1 / 30.7$ & 0.604 & 0.199 & \\
\hline & GH 3 & & $7.8 / 89.7$ & 0.487 & 0.064 & \\
\hline & GH 4 & & $8.9 / 46.1$ & 0.492 & 0.129 & \\
\hline \multirow[t]{4}{*}{ Layout 3} & GH 1 & \multirow[t]{4}{*}{1200} & $10.2 / 38.4$ & 0.553 & 0.168 & \multirow[t]{4}{*}{4.554} \\
\hline & GH 2 & & $8.8 / 39.2$ & 0.498 & 0.147 & \\
\hline & GH 3 & & 7.0/113.9 & 0.462 & 0.047 & \\
\hline & GH 4 & & $9.7 / 44.1$ & 0.527 & 0.144 & \\
\hline \multirow[t]{4}{*}{ Layout 4} & GH 1 & \multirow[t]{4}{*}{1800} & $11.1 / 44.3$ & 0.485 & 0.160 & \multirow[t]{4}{*}{3.989} \\
\hline & GH 2 & & $10.2 / 40.4$ & 0.438 & 0.161 & \\
\hline & GH 3 & & $10 / 290$ & 0.288 & 0.027 & \\
\hline & GH 4 & & $9.3 / 83.7$ & 0.348 & 0.080 & \\
\hline
\end{tabular}

Both configurations that accompanied closely TP (Layout 2 and 3 ), although providing the lowest warm-up periods, lead to the highest values of energy consumption. TEC associated to Layouts 2 and 3 are, respectively, $2.3 \%$ and $4.7 \%$ higher than TEC induced by reference position (Layout 1 ). The worst energetic performances of these solutions are strongly related to heat dispersion by convection. Although these arrangements were considered in order to concentrate the group of heaters on the areas that need a higher heat supply at start-up period, due to the high temperature differences along the die, the heat is diverted by convection to colder areas, leading to an extra effort of the heaters. This feature is in accordance with the short duty cycles obtained for all resistances in these particular layouts, with periods of time of switch-on and switch-off of similar magnitude.

The relative position of heaters that leads to the best results is the symmetrical configuration (Layout 4), allowing up to $8.3 \%$ on energy savings over reference position. This last solution does not shorten the heating-up period, but allows an overall reduction on power consumption per hour during manufacturing stage. Aiming to refine this last solution, a new simulation was performed considering a symmetric relative position of eight groups of heaters (16 resistances with $200 \mathrm{~W}$ each) with the same total power of the previous layouts. Heaters position in the new layout (Layout 5 ) is shown in Fig. 6 and the resultant energetic performance of the heating system, obtained by the same methodology, is displayed in graph of Fig. 7 and Table 2 .

Obtained results for the symmetrical configuration of 8 groups of heaters are quite similar to those achieved with half of the resistances (Layout 4). Total energy consumption is slight higher than that provided by the previous arrangement, leading to minor energy savings with regard to reference layout (5.1\%), but allows a more accurate temperature profile along the die due to increasing number of temperature controls. For instance, groups of heaters 5 and 6 , located respectively at $400 \mathrm{~mm}$ and $300 \mathrm{~mm}$ of die exit, are

Die Inlet

Die Outlet

LAYOUT 5

Fig. 6. Layout 5: symmetrical position of eight groups of heaters of $2 \times 200 \mathrm{~W}$ along the die.

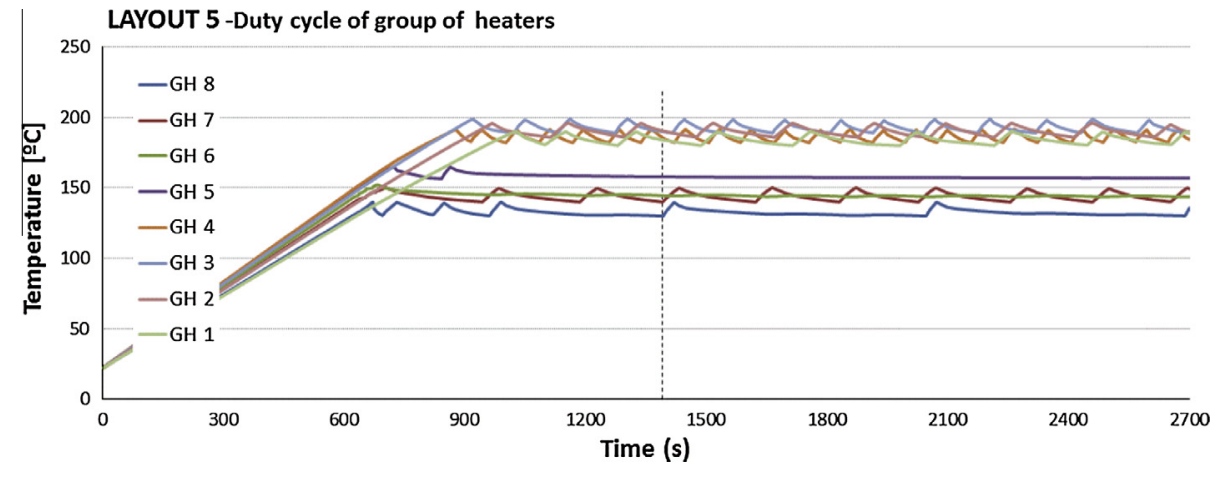

Fig. 7. Duty cycle of 8 groups of heaters for Layout 5 obtained by FEA simulation. 
Table 2

Warming-up period, duty cycles, power consumptions and total energy consumption of 8 groups of heaters $(2 \times 200 \mathrm{~W})$ for Layout 5 .

\begin{tabular}{|c|c|c|c|c|c|c|}
\hline Layout & Heaters & $T_{W}(\mathrm{~s})$ & Duty cycle (s) & $\mathrm{PC}_{\mathrm{W}}(\mathrm{kW} \mathrm{h})$ & $\mathrm{PC}_{\mathrm{M}}(\mathrm{kWh})$ & TEC $(\mathrm{kW})$ \\
\hline \multirow[t]{8}{*}{ Layout 5} & GH 1 & 1390 & $31.6 / 210.1$ & 0.301 & 0.052 & 4.128 \\
\hline & GH 2 & & $41.4 / 146.2$ & 0.281 & 0.088 & \\
\hline & GH 3 & & $27.9 / 100.8$ & 0.284 & 0.087 & \\
\hline & GH 4 & & $26.4 / 55.8$ & 0.291 & 0.128 & \\
\hline & GH 5 & & $-1-$ & 0.212 & 0 & \\
\hline & GH 6 & & $-1-$ & 0.193 & 0 & \\
\hline & GH 7 & & $38.4 / 171.6$ & 0.220 & 0.073 & \\
\hline & GH 8 & & $25.8 / 620.2$ & 0.218 & 0.016 & \\
\hline
\end{tabular}

only switched-on during warm-up period, which means that the heat produced by adjacent heaters and polymerisation reaction of resin matrix is plenty enough to maintain the temperature, in this region of the die, within the range limits of reference TP. Moreover, due to a more distributed heat power, heating-up stage is reduced up to $23 \%$, which allows an increase on productivity.

Layout 5 corresponds to the best compromise solution allowing both a reduction of starting-up period and further savings on energy consumption. In addition, the productivity is increased and the control of the process is improved, conducting to a better product quality.

\section{Conclusions}

Previous work allowed to conclude that the use of embedded cylindrical resistances, instead of external planar heaters, leads to a drastic reduction of the power consumption on the die heating system. However, the relative position of the cylindrical resistances may play an important role on the heating system, providing a better distribution of the heat along the die length and minimising the service time of the embedded resistances. On the basis of obtained results, the following conclusion can be drawn:

- The energy consumption can be reduced significantly (more than $8 \%$ ) through an adequate location of the embedded heaters.

- The energy consumption of the process, after warm-up period, not depends significantly neither on the number of the heaters used nor on its power, because each pair of cylindrical resistances only switches-on when the temperature drops enough to activate the control system.

- However, a larger number of heaters allows to reduce the warm-up period, reducing the lead-time and costs of each order.

- FEA is a reliable and not time-consuming method able to predict the power consumption of die heating system, allowing the optimisation of the relative position of the heaters along the die.

- The improvements achieved by this work allow to reduce the power requirements on pultrusion process, minimising industrial costs while increasing eco-efficiency ratios.

Further studies in this field are foreseen, considering a larger number of heaters, aimed at getting a better understanding on how the relative position of the heaters might be improved towards further savings on power consumption and warm-up periods.

\section{Acknowledgements}

The technical support of ALTO, Perfis Pultrudidos Lda., and the financial support of NSRF -National Strategic Reference Framework- is gratefully acknowledged.

\section{References}

[1] Hollaway LC. A review of the present and future utilisation of FRP composites in the civil infrastructure with reference to their important in-service properties. Constr Build Mater 2010;24:2419-45.

[2] Shaw-Stewart D, Sumerak JE. The pultrusion process. In: Starr Trevor F, editor. Pultrusion for engineers. Abington Cambridge, UK: Woodhead Publishing Ltd.; 2000.

[3] <http://www.martinpultrusion.com/technology.html> (11.07.12).

[4] Joshi SC, Lam YC, Zaw K. Optimization for quality thermosetting composites pultrudate through die heater layout and power control. In: Proceedings of 16 th international conference on composite materials - ICCM16, Kyoto, Japan; 8-13 July 2007.

[5] Suratno BR, Ye L, Mai YW. Simulation of temperature and curing profiles in pultruded composite rods. Compos Sci Technol 1998;58:191-7.

[6] Valliappan M, Roux JA, Vaughan JG, Arafat ES. Die and post-die temperature and cure in graphite/epoxy composites. Composites: Part B 1996;27B:1-9.

[7] Moschiar SM, Reboredo MM, Vazquez A. Pultrusion processing. In: Cheremisinoff Nicholas P, editor. Advanced polymer processing operations. New Jersey, USA: Noyes Publications; 1998.

[8] Sarrionandia M, Mondragón I. Heat transfer for pultrusion of a modified acrylic/glass reinforced composite. Polym Compos 2002;23:21-7.

[9] Safonov AA, Suvorova YV. Optimization of the pultrusion process for a rod with a large diameter. J Machinery Manuf Reliab 2009;38:572-8.

[10] Gorthala R, Roux JA, Vaughan JG. Resin flow, cure and heat transfer analysis for pultrusion process. J Compos Mater 1994;28:486-506.

[11] Liu XL, Hillier W. Heat transfer and cure analysis for the pultrusion of a fiberglass-vinyl ester I beam. Compos Struct 1999;47:581-8.

[12] Liu XL, Crouch IG, Lam YC. Simulation of heat transfer and cure in pultrusion with a general-purpose finite element package. Compos Sci Technol 2000;60: 857-64.

[13] Joshi SC, Lam YC. Three-dimensional finite-element/nodal-control-volume simulation of the pultrusion process with temperature-dependent material properties including resin shrinkage. Compos Sci Technol 2001;61:1539-47.

[14] Lam YC, Li J, Joshi SC. Simultaneous optimization of die-heating and pull-speed in pultrusion of thermoset composites. Polym Compos 2003;24:199-209.

[15] Joshi SC, Lam YC, Tun UW. Improved cure optimization in pultrusion with preheating and die-cooler temperature. Composites Part A 2003;34:1151-9.

[16] Joshi SC, Lam YC. Integrated approach for modelling cure and crystallization kinetics of different polymers in 3D pultrusion simulation. J Mater Process Technol 2006;174:178-82.

[17] Chen X, Xie H, Chen H, Zhang F. Optimization for CFRP pultrusion process based on genetic algotithm-neural network. Int J Mater Forum 2010;3: S1391-9.

[18] Franco A, Romoli L. Characterization of laser energy consumption in sintering of polymer based powders. J Mater Process Technol 2012;212:917-26.

[19] Pusavec F, Krajnik P, Kopac J. Transitioning to sustainable production - Part I: application on machining technologies. J Clean Prod 2010;18:174-84.

[20] Schmidheiny S. Changing course - a global business perspective on development and the environment, world business council for sustainable development. London, England: The MIT Press; 1992.

[21] Khan WA, Methven J. Determination of duty cycle in thermoset pultrusion. In: Proceedings of 17th international conference on composite materials ICCM17-, Edinburgh, UK; 27-31 July 2009.

[22] Sumerack JE. Experimental measurements of pultrusion die/heater interface effects on process stability and economics. In: Proceedings of COMPOSITES 2002 convention and trade show, Atlanta, USA; 25-27 September 2002.

[23] Srinivasagupta D, Kardos JL. Ecologically and economically conscious design of the injected pultrusion process via multi-objective optimization. Model Simul Mater Sci Eng 2004;12:S205.

[24] Santos LS, Pagano RL, Biscaia EC, Calado VMA. Optimum heating configuration of pultrusion process. Comput Aided Chem Eng 2009;27:705-10.

[25] Santos LS, Calado VMA, Giovanelli L, Nóbrega M, Pagano R, Biscaia E. Application of a CFD-based tool to optimise an industrial pultrusion process. In: Proceedings of 2 nd international conference on engineering optimization, Lisbon, Portugal; 6-9 September 2010.

[26] Silva FGS, Ferreira F, Costa C, Ribeiro MCS, Castro ACM. Comparative study about heating systems for pultrusion process. Composites: Part B 2012; 43(4):1823-9. 